\title{
Treatment with PPAR $\alpha$ Agonist Clofibrate Inhibits the Transcription and Activation of SREBPs and Reduces Triglyceride and Cholesterol Levels in Liver of Broiler Chickens
}

\author{
Lijun Zhang, ${ }^{1}$ Chunyan Li, ${ }^{1}$ Fang Wang, ${ }^{1}$ Shenghua Zhou, ${ }^{1}$ \\ Mingjun Shangguan, ${ }^{1}$ Lina Xue, ${ }^{1}$ Bianying Zhang, ${ }^{1}$ Fuxiang Ding, \\ Dequan Hui, ${ }^{2}$ Aihua Liang, ${ }^{2}$ and Dongchang $\mathrm{He}^{1}$ \\ ${ }^{1}$ Institute of Animal Husbandry and Veterinary Sciences, Shanxi Provincial Academy of Agricultural Sciences, Taiyuan 030031, China \\ ${ }^{2}$ Institute of Biotechnology of Shanxi University, Key Laboratory of Chemical Biology and Molecular Engineering of \\ Ministry of Education, Taiyuan 030006, China
}

Correspondence should be addressed to Dongchang He; sxnkyhdc@163.com

Received 10 July 2015; Revised 16 September 2015; Accepted 28 October 2015

Academic Editor: Stéphane Mandard

Copyright (C) 2015 Lijun Zhang et al. This is an open access article distributed under the Creative Commons Attribution License, which permits unrestricted use, distribution, and reproduction in any medium, provided the original work is properly cited.

PPAR $\alpha$ agonist clofibrate reduces cholesterol and fatty acid concentrations in rodent liver by an inhibition of SREBP-dependent gene expression. In present study we investigated the regulation mechanisms of the triglyceride- and cholesterol-lowering effect of the PPAR $\alpha$ agonist clofibrate in broiler chickens. We observed that PPAR $\alpha$ agonist clofibrate decreases the mRNA and protein levels of LXR $\alpha$ and the mRNA and both precursor and nuclear protein levels of SREBP1 and SREBP2 as well as the mRNA levels of the SREBP1 (FASN and GPAM) and SREBP2 (HMGCR and LDLR) target genes in the liver of treated broiler chickens compared to control group, whereas the mRNA level of INSIG2, which inhibits SREBP activation, was increased in the liver of treated broiler chickens compared to control group. Taken together, the effects of PPAR $\alpha$ agonist clofibrate on lipid metabolism in liver of broiler chickens involve inhibiting transcription and activation of SREBPs and SREBP-dependent lipogenic and cholesterologenic gene expression, thereby resulting in a reduction of the triglyceride and cholesterol levels in liver of broiler chickens.

\section{Introduction}

The lipid metabolism in mammalian is regulated mainly by transcription factors including peroxisome proliferatoractivated receptor alpha (PPAR $\alpha)$, liver $\mathrm{X}$ receptor alpha $(\mathrm{LXR} \alpha)$, and sterol regulatory element-binding proteins (SREBPs) [1-6]. PPAR $\alpha$ is a ligand-activated transcription factor known to regulate expression of numerous genes involved in fatty acid uptake and oxidation, ketogenesis, gluconeogenesis, cholesterol catabolism, and lipoprotein metabolism [7, 8]. Transcriptional regulation of genes by $\operatorname{PPAR} \alpha$ is mediated by forming a heterodimer with the retinoid X receptor (RXR) and subsequent binding of the PPAR $\alpha / R X R$ heterodimer to peroxisome proliferator response element (PPRE) presenting in the promoter of target genes. Ligands of PPAR $\alpha$ are fatty acids and fatty acid derivatives (eicosanoids) as well as a heterogenous group of synthetic compounds including the fibrate class of lipid lowering drugs (clofibrate, fenofibrate, bezafibrate, and gemfibrozil) $[7,8]$. The lipid-lowering mechanism of fibrates involves activation of PPAR $\alpha$ in the liver leading to an upregulation of genes involved in cellular fatty acid uptake, carnitine-dependent mitochondrial fatty acid uptake, and mitochondrial and peroxisomal $\beta$-oxidation and, thereby, to an increased fatty acid catabolism and decreased triacylglycerol concentrations in liver and blood $[7,8]$. In addition, it has been shown that activation of PPAR $\alpha$ by fibrates and oxidized fatty acids decreases the expression of genes involved in lipid synthesis and lipid uptake in the liver [9-12] indicating that the lipid-lowering effect of fibrates also involves reduction of lipid synthesis.

The LXR $\alpha$ is implicated in regulation of intracellular cholesterol levels and lipogenesis in mammals [13-15]. LXR $\alpha$ 
functions by forming obligate heterodimers with the retinoid $\mathrm{X}$ receptor (RXR) and subsequently binds to LXR response element (LXRE) within the promoters of the target genes, thereby regulating gene expression [14]. It was reported that fatty acid metabolism in rat is regulated by cross-talk between PPAR $\alpha$ and LXR $\alpha$, in which PPARs suppress SREBP1c activation through inhibition of LXR signaling [16-18].

The SREBPs are transcription factors regulating the transcription of genes related to lipid synthesis and uptake $[5,6$, 19], from which the SREBP1c isoform preferentially activates genes required for fatty acid and triacylglycerol synthesis like fatty acid synthase (FASN) and glycerophosphate acyltransferase, and mitochondrial (GPAM) $[1,20]$, and the SREBP2 isoform stimulates mainly genes involved in cholesterol synthesis and uptake such as 3-hydroxy-3-methylglutaryl CoA reductase (HMGCR) and low-density lipoprotein receptor $(L D L R)$ [2, 19]. SREBPs are synthesized as inactive precursor proteins and form a complex with SREBP cleavage activating protein (SCAP), which is initially bound to the rough endoplasmic reticulum membrane by the insulininduced genes (INSIGs). Activation of SREBPs involves the release of the SCAP-SREBP complex from INSIGs and its translocation to the Golgi, where the N-terminus of SREBP is cleaved by proteolysis and translocated to the nucleus where it can bind to specific sterol response elements (SREs) in the promoters of target genes, thereby activating their transcription $[5,6]$.

It has been shown that feeding PPAR $\alpha$ activators to rats or treatment of rat liver cells with PPAR $\alpha$ activators causes an inhibition of SREBP1 and SREBP2 activation and an upregulation of INSIG1 and INSIG2 [9-11] suggesting that the decreased expression of genes involved in lipid synthesis and lipid uptake in response to fibrates and oxidized fatty acids is mediated by PPAR $\alpha$. The major sites of fatty acid synthesis are adipose tissue and the liver in animals. However, the relative contribution for the whole body lipogenesis is highly variable among species. In the pigs and ruminants adipose tissue is the main lipogenic organ with minor contribution from the liver, while in the rodents and rabbits both liver and adipose tissue are important for lipogenesis [20, 21]. However in avian species the liver is the predominant lipogenic site [20, 2224] because its lipogenesis capacity markedly exceeds that of adipose tissue [25], indicating that an inhibitory effect of fibrates on hepatic lipid synthesis has a greater impact on lipid concentrations in birds than in other species. To our knowledge, however, it has not been shown whether fibrates inhibit the activation of SREBPs in the liver of birds. Therefore, the aim of the present study was to investigate the effect of the PPAR $\alpha$ agonist clofibrate on activation of hepatic SREBPs in birds by determining both expression levels of mRNA and protein of LXR $\alpha$ and SREBP1/SREBP2 and mRNA levels of the SREBP1 target genes FASN and GPAM and SREBP2 target genes HMGCR and LDLR as well as the mRNA levels of INSIG1 and INSIG2. For this end, we performed a feeding experiment with broiler chickens that were fed either a control diet or a diet supplemented with clofibrate for 4 weeks.

\section{Material and Methods}

2.1. Animals Treatment. All experimental procedures were approved by the Shanxi Administration Office of Laboratory Animals (2012011035-2). A total of 48 one-day-old Arber Acres broiler chickens were used in the experiment. Until the end of the second week, all broilers were fed with a commercial starter diet (Nutrition R\&D Center of Institute of Animal Husbandry and Veterinary Sciences, Shanxi Provincial Academy of Agricultural Sciences) containing 13.3 MJ metabolizable energy and $19.1 \%$ crude protein per kg diet. At the beginning of the third week, the broiler chickens were randomly assigned into two groups of 24 animals each. The animals of both groups were kept in groups of 8 birds/group in wire cages in a room with controlled temperature of 22$24^{\circ} \mathrm{C}$ on a $18 \mathrm{~h}$ light and $6 \mathrm{~h}$ dark cycle. The animals of the control group were fed a commercial grower diet (Nutrition R\&D Center of Institute of Animal Husbandry and Veterinary Sciences, Shanxi Provincial Academy of Agricultural Sciences), whereas animals of the clofibrate group were fed the same diet supplemented with $1 \mathrm{~g}$ clofibrate [ethyl 2-(4-chlorophenoxy)2-methylpropanoate] (TCI-Tokyo chemical Industry, Tokyo, Japan) per $\mathrm{kg}$ diet. This dose was chosen based on a recent study [26], in which a clofibrate dose of $1.5 \mathrm{~g} / \mathrm{kg}$ diet was used to treat 20-week-old laying hens for 4 weeks and caused an activation of PPAR $\alpha$ in animal liver without toxic effects. Considering health and growth of broiler chickens we chose a clofibrate dose of $1 \mathrm{~g} / \mathrm{kg}$ diet. For $1 \mathrm{~kg}$ diet $1 \mathrm{~g}$ clofibrate was dissolved in $25 \mathrm{~mL}$ sunflower oil and mixed very well with the vitamin-mineral premix, subsequently with ration of rest. The control animals received an equal volume of the vehicle. The composition of the experimental grower diets is shown in Table 1. Feed and water were supplied ad libitum during the entire experiment. Body weight and feed intake were recorded every week. Feed conversion ratio (FCR) was calculated by measurement of feed intake to body weight gain.

2.2. Sample Collection. After treatment for 4 weeks, all birds were individually weighed and then killed. Liver was excised and weighed. Aliquots of liver tissue for RNA and protein isolation as well as lipid extraction were snap-frozen in liquid nitrogen and stored at $-80^{\circ} \mathrm{C}$.

2.3. Determination of Lipid Concentrations in the Liver. For determination of triglyceride and total cholesterol concentrations in the liver, liver lipids were extracted from pooled liver tissue, with liver tissue from 3 animals contributing to each pool (about 15-20 mg from each animal for determination of triglyceride, and $10-15 \mathrm{mg}$ for determination of total cholesterol), using a mixture of n-hexane and isopropanol $(3: 2, v / v)[27]$, and aliquots of the lipid extracts were dried and dissolved in a small volume of Triton X-100 [28]. Concentrations of triglycerides and cholesterol were determined using enzymatic reagent kits (Tissue triglyceride assay kit, catalogue number E1013 and tissue total cholesterol assay kit, catalogue number E1015, Applygen Technologies Co., Ltd., Beijing, China) following the manufacturer's protocol. 
TABLE 1: Composition of the experimental grower diets.

\begin{tabular}{lcc}
\hline & $\begin{array}{c}\text { Control } \\
\text { group }\end{array}$ & $\begin{array}{c}\text { Treatment } \\
\text { group }\end{array}$ \\
\hline Components (g/kg) & 630 & \\
Maize & 25 & 629 \\
Fish meal & 30 & 30 \\
Wheat middlings & 260 & 260 \\
Soybean meal 44\% & 25 & 25 \\
Sunflower oil & 10 & 10 \\
Limestone powder & 14.8 & 14.8 \\
Calcium hydrogen phosphate & 2.5 & 2.5 \\
Sodium chloride & 1.2 & 1.2 \\
Vitamin-mineral mix ${ }^{1}$ & 1 & 1 \\
DL-methionine & 0.5 & 0.5 \\
Choline chloride 50\% & - & 1.0 \\
Clofibrate & & \\
Crude nutrients and energy content & 89.84 & 89.84 \\
Dry matter (\%) & 13.3 & 13.3 \\
Metabolizable energy (MJ/kg) & 19.1 & 19.1 \\
Crude protein (\%) & 5.5 & 5.5 \\
Crude fat (\%) & 2.0 & 2.0 \\
Linoleic acid (\%) & 2.6 & 2.6 \\
Crude fibre (\%) & 0.98 & 0.98 \\
Calcium (\%) & 0.49 & 0.49 \\
Available phosphorus (\%) & & \\
\hline
\end{tabular}

${ }^{1}$ The vitamin-mineral mix provided per kg of diet: $3.3 \mathrm{mg}$ retinol, $0.033 \mathrm{mg}$ cholecalciferol, $13.34 \mathrm{mg}$ D- $\alpha$-tocopheryl acetate, $0.5 \mathrm{mg}$ menadione, $2.2 \mathrm{mg}$ thiamine, $6.6 \mathrm{mg}$ riboflavin, $5.5 \mathrm{mg}$ pyridoxine, $0.01 \mathrm{mg}$ cobalamin, $13.5 \mathrm{mg}$ pantothenate, $0.2 \mathrm{mg}$ biotin, $1.0 \mathrm{mg}$ folic acid, $44 \mathrm{mg}$ nicotinic acid, $350 \mathrm{mg}$ magnesium, $9.6 \mathrm{mg}$ copper, $100 \mathrm{mg}$ iron, $108 \mathrm{mg}$ manganese, $88 \mathrm{mg}$ zinc, $0.23 \mathrm{mg}$ selenium, and $0.4 \mathrm{mg}$ iodine.

\subsection{Total RNA Isolation and Quantitative Real-Time PCR Analysis ( $q P C R)$}

2.4.1. RNA Isolation. For RNA isolation and Real-Time $\mathrm{qPCR}$ analysis we used the same protocol described by Keller et al. [29] with minor modifications. Briefly, total RNA was isolated from $20-30 \mathrm{mg}$ of frozen liver tissue using Trizol Reagent (Shanghai Invitrogen Biotechnology Co., Ltd., China) according to the manufacturer's protocol. RNA concentration and purity were estimated by measuring the optical density (OD) at 260 and $280 \mathrm{~nm}$, respectively, using NanoDrop Spectrophotometer ND-1000 (Thermo Fisher Biochemical Product (Beijing) Co., Ltd., China). RNA used for RT-PCR had an A260/A280 ratio $1.94 \pm 0.05$. RNA integrity and quality were evaluated by $1.2 \%$ agarose gel electrophoresis and all samples had intact bands corresponding to the $18 \mathrm{~S}$ and $28 \mathrm{~S}$ ribosomal RNA subunits (Supplementary Figure 1 in Supplementary Material available online at http://dx.doi.org/ 10.1155/2015/347245).

2.4.2. cDNA Synthesis. The first-strand cDNA was synthesized using $1.2 \mu \mathrm{g}$ of total RNA, $1 \mu \mathrm{L}$ dT18 $(100 \mathrm{pmol} / \mu \mathrm{L})$ primer (TaKaRa, Dalian, China), $1.25 \mu \mathrm{L}$ dNTP mix (10 mM) (Thermo Fisher Biochemical Product (Beijing) Co., Ltd., China), $5 \mu \mathrm{L}$ buffer ( $5 \mathrm{x}$ reaction buffer), $0.3 \mu \mathrm{L} \mathrm{M}-\mathrm{MuLV}$ Reverse Transcriptase (200 units/ $\mu \mathrm{L}$ ) (Thermo Fisher Biochemical Product (Beijing) Co., Ltd., China), and $x \mu$ L DEPC treated water to make a $25 \mu \mathrm{L}$ final reaction volume and incubated at $42^{\circ} \mathrm{C}$ for $60 \mathrm{~min}$, following a final inactivating step at $60^{\circ} \mathrm{C}$ for 10 min in Bio-Rad C1000 Touch thermal cycler PCR (Bio-Rad Laboratories, (Beijing) Co., Ltd., China).

2.4.3. Primer Design and Test of Amplification Efficiency. Gene-specific primer pairs (Table 2) synthesized by TaKaRa (Dalian, China) were designed using Clone Manager Professional software 9.2. All primer pairs were designed to have melting temperature of about $60^{\circ} \mathrm{C}$. The primer pairs, if possible, were designed to be located in different exons. To estimate amplification efficiency of primer, a cDNA pool from each sample was made and serial dilution for standard curve for each primer was prepared. The qRT-PCR reactions were carried out in a $0.1 \mathrm{~mL}$ tube (Qiagen, Germany, cat. number 981103) each with a total volume of $20 \mu \mathrm{L}$ and in a RotorGene Q 2plex HRM System (Qiagen, Germany, cat. number 9001630). Each PCR mixture contained $2 \mu \mathrm{L}$ cDNA, $0.4 \mu \mathrm{L}$ each of $10 \mu \mathrm{M}$ forward and reverse primers, $10 \mu \mathrm{L}$ Maxima SYBR Green qPCR Master Mix (Thermo Fisher Biochemical Product (Beijing) Co., Ltd., China), and 7.2 $\mu$ L DNase/RNase free water. The qRT-PCR protocol was as follows: $3 \mathrm{~min}$ at $95^{\circ} \mathrm{C}$, followed by $30-45$ cycles, a two-step PCR consisting of $5 \mathrm{sec}$ at $95^{\circ} \mathrm{C}$ for denaturation and $20 \mathrm{sec}$ at $60^{\circ} \mathrm{C}$ for annealing and extension. Subsequently, melting curve analysis was performed from $50^{\circ} \mathrm{C}$ to $95^{\circ} \mathrm{C}$ to check for the presence of a single PCR product or contamination during the PCR reaction. In addition, the amplifications of specific PCR products were confirmed by performing a $2 \%$ agarose gel electrophoresis stained with GelRed Nucleic Acid Gel Stain (Biotium, (Beijing) Co., Ltd., China). After PCR running Ct (threshold cycle) values were collected by Rotorgene Software 5.0 (Qiagen, Germany) with an automated analysis and exported in Excel files. The correlation coefficient $\left(R^{2}\right)$ and the slops were calculated using standard curve. The slop was used to determine the efficiency of each primer (Supplementary Table 1).

2.4.4. Selection of Candidate Reference Genes. Reference genes were chosen from some published literatures in rat, pig, or cow [29-31]. Reference gene stability and the normalization factor were determined by performing GeNorm analysis described by Keller et al. [29] and Vandesompele et al. [32]. The candidate gene possessing $M$-value below 1.5 is considered as stably expressed gene. The optimal number of reference genes is determined by pairwise variation $(V)$ analysis with a $V$-value below 0.15 [33]. After PCR running Ct values of reference genes were collected and then exported in Excel files. Ct values were transformed to relative quantification data using the equation $2^{\Delta \mathrm{Ct}}$, where $\Delta \mathrm{Ct}=(\operatorname{minCt}-\mathrm{Ct})$, where minCt is the lowest $\mathrm{Ct}$ value over a range of samples, and $\mathrm{Ct}$ is sample $\mathrm{Ct}$. The sample with minimum expression was used as the calibrator with a set value of 1 . Subsequently, 
TABLE 2: Characteristics and performance data of the primers used for reference gene-stability measure $M$ and quantitative real-time PCR analysis.

\begin{tabular}{|c|c|c|c|}
\hline Gene name & Primer sequence (forward, reverse) & Product size (bp) & NCBI GenBank \\
\hline \multicolumn{4}{|c|}{ Reference genes } \\
\hline$A T P 5 B$ & GGTGTGCAGAAGATCCTTCA, GATCTGCTTGAAGCCCTTGA & 216 & NM_001031391 \\
\hline TOP1 & GCATCATGCCAGAAGACATC, CTTGAGCTAGGGTTCAACATT & 175 & NM_205110 \\
\hline$M D H 1$ & GCATGGAGAGGAAGGATTTG, GAAGTCACACCAAGCTTCAG & 241 & NM_001006395 \\
\hline RPL13 & GTTCGTGCTGGCAGAGGAT, GACAGCTGAGTTGCCATCTT & 245 & NM_204999 \\
\hline YWHAZ & TGTGGAGCAATCACAACAGG, GTTGTCTCTCAGTAACTGCAT & 250 & NM_001031343 \\
\hline GAPDH & CACTTCAAGGGCACTGTCAA, CTCATGGTTGACACCCATCA & 252 & NM_204305 \\
\hline \multicolumn{4}{|l|}{ Target genes } \\
\hline$P P A R \alpha$ & GGAGTTTAAGTGACCGCTCT, CTGATCCATCAGATCCTGGA & 230 & NM_001001464 \\
\hline CPT1A & ACTCTCCAGCACGTGAAAGA, CCTGCAGTAAGAGCTGCTAA & 118 & NM_001012898 \\
\hline SREBF1 & ACCTGGCAGCCAAGGCAT, GACTCAGCCATGATGCTTCT & 168 & NM_204126 \\
\hline FASN & CTCCTTGAAGGTGGTTTGCA, CCTCCATGTTTCCTGCTTTC & 219 & NM_205155 \\
\hline GPAM & GTTGAGACAGCAGCAGTTTTT, CCTTCAATTATGCGATCGTAG & 177 & XM_421757 \\
\hline SREBF2 & CATTCTGACCACAATGCCAG, GGTCCTTCAGCTCAATGATC & 176 & AJ414379 \\
\hline$H M G C R$ & GCTTAGCCTTTCTCCTTGCT, CCAGATTGTTTCCTGCAGCA & 250 & XM_422225 \\
\hline$L D L R$ & CACTCAGTGCCACCATTTGG, CTGCGACGGAACGTCCAAG & 203 & NM_204452 \\
\hline INSIG1 & CCAACAATGTCCAGCTGTCC, CACCATTATATACAAGGAACTG & 147 & NM_001030966 \\
\hline INSIG2 & GGATTTTGCCAACAATATCCAG,TGTAGACCAGAAGCTGTGACA, & 149 & NM_001031261 \\
\hline$L X R \alpha$ & CCAAGATGCTGGGAAATGAAGC, ATATACATGTCCATCTCACAC & 193 & NM_204542 \\
\hline
\end{tabular}

Sterol regulatory element binding transcription factors 1 and 2 (SREBF1 and SREBF2); peroxisome proliferator-activated receptor alpha (PPAR $)$; carnitine palmitoyltransferase 1A (CTP1A); fatty acid synthase (FASN); glycerol-3-phosphate acyltransferase, mitochondrial (GPAM); 3-hydroxy-3-methylglutaryl CoA reductase $(H M G C R)$, low-density lipoprotein receptor (LDLR); Liver X-Receptor alpha (LXR $)$; insulin induced genes 1 and 2 (INSIG1 and INSIG2); ATP synthase, $\mathrm{H}+$ transporting, mitochondrial F1 complex, beta polypeptide (ATP5B); topoisomerase (DNA) I (TOP1); malate dehydrogenase 1, NAD (soluble) (MDH1); ribosomal protein L13 (RPL13); tyrosine 3-monooxygenase/tryptophan 5-monooxygenase activation protein, zeta polypeptide (YWHAZ); glyceraldehyde-3-phosphate dehydrogenase $(G A P D H)$.

$2^{\Delta \mathrm{Ct}}$ results were used as input data for Microsoft excel-based software geNorm and normalization factors were calculated by the geNorm software. The $M$-value and $V$-value as well as ranking reference genes for stability of expression were reported as in the figure by geNorm output (Supplementary Figures 2 and 3). Based on the $M$-values and $V$-values, out of six tested potential reference genes including $M D H 1, R P L 13$, $G A P D H, Y W H A Z, A T P 5 B$, and TOP1, the five reference genes $M D H 1, R P L 13, G A P D H, Y W H A Z$, and ATP5B with $M<$ 1.5 and $V 5 / V 6=0.154$, which was near the proposed cutoff value of 0.15 , were used to calculate a gene expression normalization factor for each sample.

2.4.5. Data Analysis. After PCR running the relative quantification of target genes was performed using $2^{\Delta \mathrm{Ct}}$ method described above and then normalized by the normalization factor using geNorm. The qRT-PCR data for each gene prior to statistical analysis were normalized to the control by dividing each data point by the mean of the control group. This resulted in a mean of 1 for the control and an expression ratio for the treated group compared to the control group.

2.5. Immunoblot Analysis. Nuclear extracts were prepared from $100 \mathrm{mg}$ pooled liver tissue, with liver tissue from 3 animals contributing to each pool (about 30-40 mg from each animal), using Nuclear Extract Kit (Active Motif, (Shanghai) Co., Ltd., China) according to the manufacturer's protocol. Protein content was determined by the bicinchoninic acid protein assay kit (TaKaRa, Dalian, China) and BSA as standard. Proteins were separated by SDSPAGE and electrotransferred to nitrocellulose membranes (Bio-Rad Laboratories, (Beijing) Co., Ltd., China). The blots were incubated overnight at $4^{\circ} \mathrm{C}$ with primary antibodies against rabbit polyclonal SREBP1 (1:500, Santa Cruz, USA), SREBP2 (1:500, Santa Cruz, USA), and LXR $\alpha$ (1:500, Affinity Bioreagents, USA), as well as mouse monoclonal $\beta$-actin $(1: 10.000$, Abcam, Cambridge, UK) as internal control for normalization. The membranes were washed and then incubated with a horseradish peroxidase-conjugated secondary anti-rabbit-IgG or anti-mouse IgG antibody (1:10.000 Santa Cruz, USA) at room temperature. Afterward, blots were developed using ECL Plus (Bio-Rad Laboratories, (Beijing) Co., Ltd., China). Band intensities were evaluated densitometrically using ChemiDoc MP Image Lab System and Image Lab Software 5.1 according to the manufacturer's guideline (http://www.bio-rad.com/webroot/web/pdf/lsr/literature/10022469.pdf) (Bio-Rad Laboratories, (Beijing) Co., Ltd., China).

2.6. Statistics Analysis. Data were expressed as means \pm SEM (standard error of mean). Statistical analysis was performed using SAS 9.1.3 statistical software (SAS Institute, Inc., 2001). Data of experiment were analyzed for normality of distribution (Anderson-Darling test). Because all data showed 
TABLE 3: Concentrations of triglycerides and cholesterol in the liver of broiler chickens fed diets without (control) or with $0.1 \%$ clofibrate for 4 weeks.

\begin{tabular}{lcc}
\hline Lipid & Control & Clofibrate \\
\hline Triglycerides $(\mu \mathrm{mol} / \mathrm{g})$ & $74.6 \pm 4.56$ & $35.5 \pm 2.83^{*}$ \\
Cholesterol $(\mu \mathrm{mol} / \mathrm{g})$ & $11.2 \pm 0.40$ & $7.5 \pm 0.98^{*}$ \\
\hline
\end{tabular}

Values are means \pm SEM, $n=3$ pools/group with each pool representing 3 animals.

${ }^{*}$ Significantly different from control $(P<0.05)$.

a normal distribution, one-way ANOVA was applied to evaluate the effect of treatment. Means of the treatment (clofibrate group) were compared with the control group by Student's $t$-test. Significant difference was declared with a $P<$ 0.05 .

\section{Results}

3.1. Body Weights, Feed Intake, and Feed Conversion Ratio. Feeding of the diet with clofibrate did not reduce performance characteristics of broiler chickens. Initial body weight of the experimental animals (IBWE) and final body weights (FBW), average daily feed intake (ADF), and feed conversion ratio (FCR) did not differ between the control group and the clofibrate group (IBWE: $314 \pm 10$ versus $319 \pm 11 \mathrm{~g}$; FBW: $1946 \pm 45$ versus $1966 \pm 43 \mathrm{~g}$; ADF: $123 \pm 2$ versus $108 \pm 2 \mathrm{~g}$; FCR: $1.93 \pm 0.06$ versus $2.06 \pm 0.04 ; n=24$ /group).

3.2. Concentrations of Triglyceride and Cholesterol in the Liver. The concentrations of triglyceride and cholesterol were significantly lower in the liver of broiler chickens treated with clofibrate than that of the control group (Table 3).

\subsection{Relative $m R N A$ Concentrations of PPAR $\alpha$ and the PPAR $\alpha$} Target Gene CPT1A in the Liver. To evaluate activation of hepatic PPAR $\alpha$ by clofibrate, we determined the mRNA level of the classical PPAR $\alpha$ target gene CPT1A in the liver. As shown in Figure 1, the mRNA level of CPT1A in the liver was about $35 \%$ greater in the clofibrate group than in the control group $(P<0.05)$ indicating activation of hepatic PPAR $\alpha$ by clofibrate. The mRNA level of PPAR $\alpha$ in the liver did not differ between broiler chickens of the control group and the clofibrate group.

3.4. Relative mRNA Concentrations of SREBFs and Their Target Genes in the Liver. To investigate whether activation of hepatic PPAR $\alpha$ is accompanied by a reduced expression of genes involved in lipid synthesis and uptake in the liver, we determined mRNA levels of SREBFs and SREBP target genes. As illustrated in Figure 2, mRNA levels of SREBF1 and SREBP1 target genes (FASN, GPAM) and SREBF2 and SREBP2 target genes (HMGCR, LDLR) in the liver of broiler chickens were approximately $20 \%$ to $50 \%$ less in the clofibrate group than in the control group $(P<0.05)$.

3.5. Relative Protein Levels of Precursor and Nuclear SREBPs in the Liver. In order to explain the reduced expression of SREBP target genes in the liver of clofibrate-treated broiler

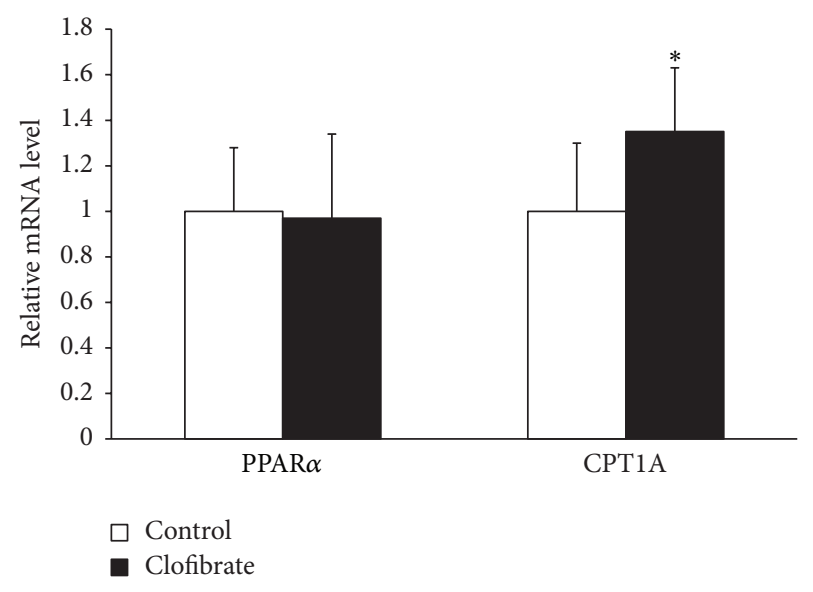

FIgURE 1: mRNA level relative to control of PPAR $\alpha$ and its target gene CPT1A in the liver of broiler chickens fed diets without (control) or with $0.1 \%$ clofibrate for 4 weeks. Values are means \pm SEM, $n=24$ /group.

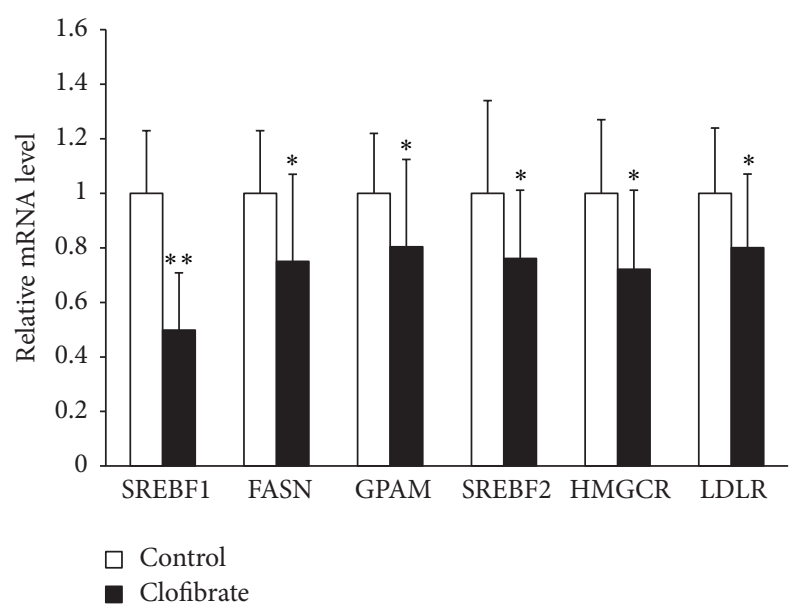

FIGURE 2: mRNA level relative to control of SREBF1, SREBF2, and SREBP1 (FASN, GPAM) and SREBP2 (HMGCR, LDLR) target genes in the liver of broiler chickens fed diets without (control) or with $0.1 \%$ clofibrate for 4 weeks. Values are means \pm SEM, $n=24$ /group.

chickens, we determined the protein levels of precursor and the transcriptionally active nuclear SREBPs in the liver. In line with the decreased mRNA levels of SREBP target genes in the liver, we found that the protein levels of precursor and nuclear SREBP1 (Figure 3(a)) and SREBP2 (Figure 3(b)) in the liver of broiler chickens were decreased (about pSREBP1 28\%, nSREBP1 21\%; pSREBP2 14\%, nSREBP2 24\%) in the clofibrate group compared to the control group $(P<0.05)$.

3.6. Relative mRNA Levels of INSIG1 and INSIG2 in the Liver. To study whether the reduced activation of SREBPs by clofibrate in the liver of broiler chickens involves upregulation of INSIGs, we determined mRNA levels of INSIG1 and INSIG2 in the liver. As demonstrated in Figure 4, the relative mRNA level of INSIG2 in the liver was about $40 \%$ greater in the clofibrate group than in the control group $(P<0.05)$, whereas that of INSIG1 did not differ between the two groups. 


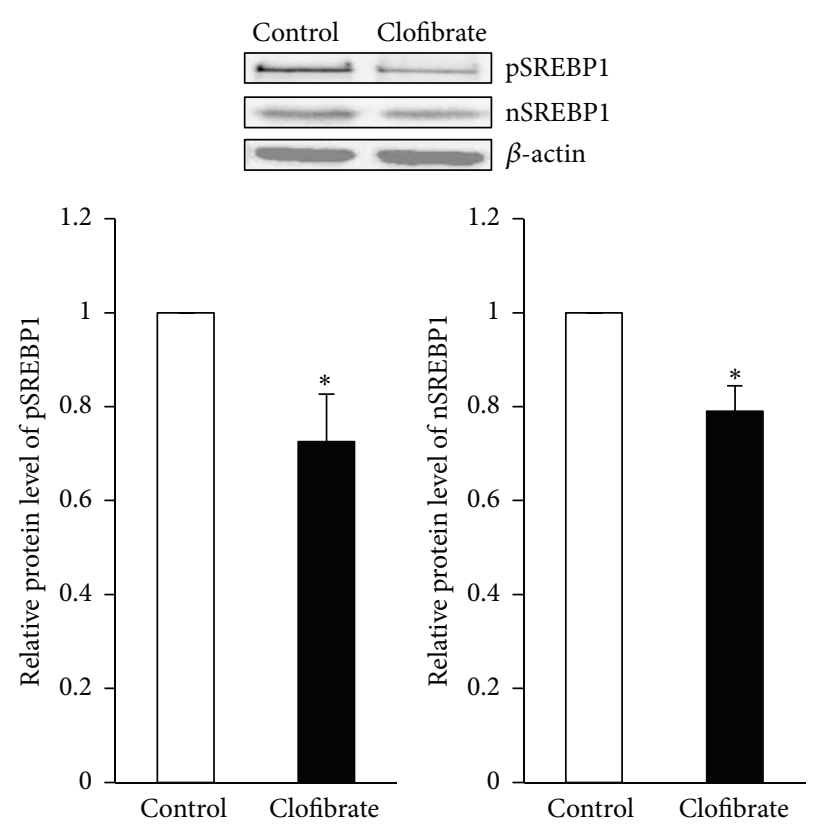

(a)

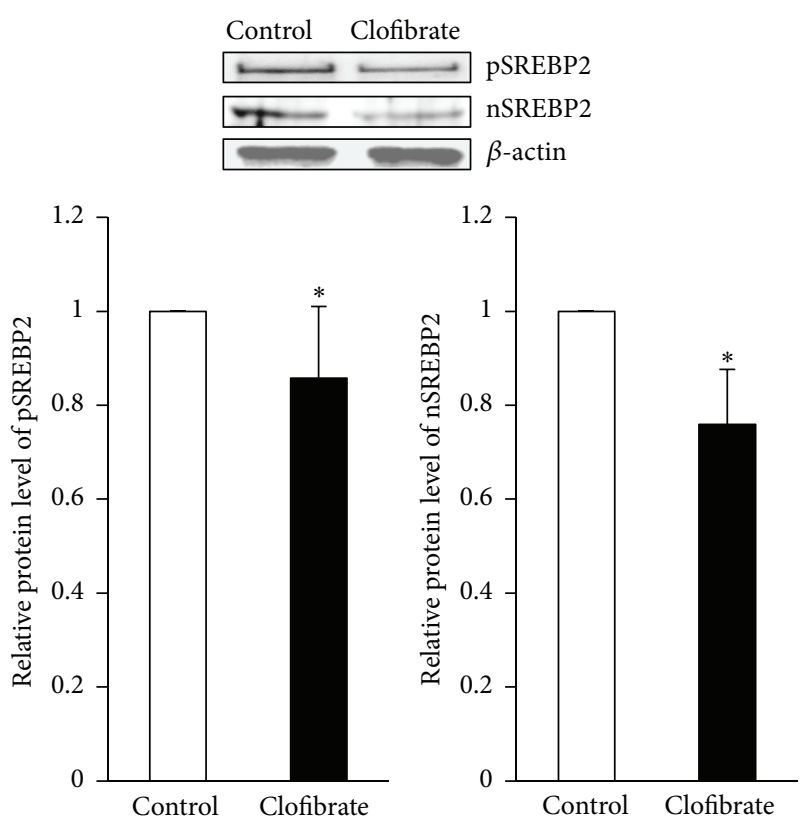

(b)

FIGURE 3: Protein levels relative to control of precursors and nuclear forms of SREBP1 and SREBP2 in the liver of broiler chickens fed diets without (control) or with $0.1 \%$ clofibrate for 4 weeks. Representative immunoblots specific to precursors and nuclear SREBP1 (a) and SREBP2 (b) and $\beta$-actin as internal control are shown for one pool per group; immunoblots for the other pools revealed similar results. Values are means \pm SEM, $n=3$ pools/group with each pool representing 3 animals.

3.7. Relative $m R N A$ and Protein Level of LXR $\alpha$ in the Liver. In order to explain the reduced expression of SREBP target genes in the liver of clofibrate-treated broiler chickens, we finally determined mRNA and nuclear protein levels of LXR $\alpha$ in the liver. We observed that both mRNA (Figure 5(a)) and nuclear protein levels of LXR $\alpha$ (Figure 5(b)) in the liver of broiler chickens were decreased (about 25\% and 35\%, resp.) in the clofibrate group compared to the control group $(P<0.05)$.

\section{Discussion}

In the present study we investigated the regulatory mechanism of the triglyceride- and cholesterol-lowering effect of the PPAR $\alpha$ agonist clofibrate in broiler chickens, a species in which the liver is the predominant site of lipogenesis. We found that clofibrate did not influence the final body weight and feed conversion ratio between the control and treatment groups but lowered the concentrations of triglyceride and cholesterol in the liver of broiler chickens. We also observed that mRNA and protein levels of LXR $\alpha$ and mRNA and both precursor and nuclear protein levels of SREBP1c and SREBP2, which are the master regulators of genes involved in lipid synthesis and uptake, as well as the expression of SREBP1c and SREBP2 target genes (FASN, GPAM, HMGCR, and LDLR) were clearly decreased in treatment group. The similar effects were found in the liver of rats and rat liver cells by treatment with PPAR $\alpha$ activators [9-11]. Numerous studies reported that SREBPs were regulated at multiple levels, namely, at the mRNA, precursor, or mature protein levels [34-37]. SREBP2

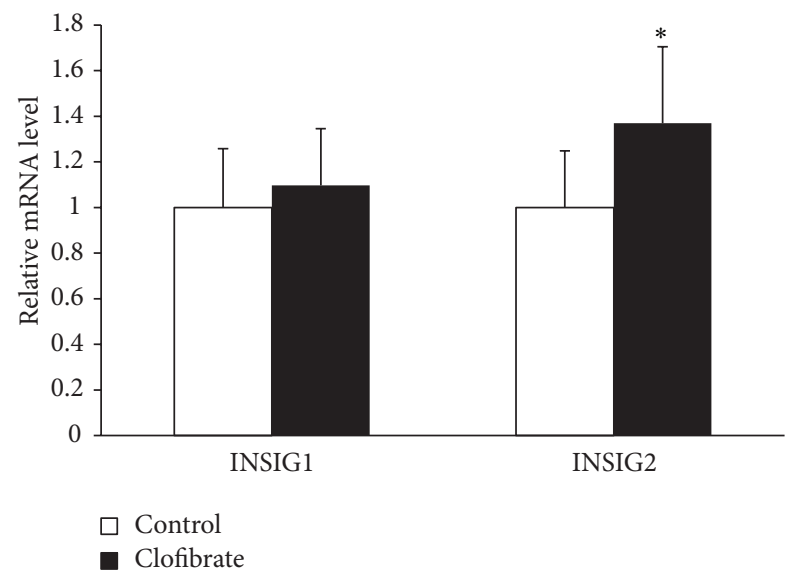

FIGURE 4: mRNA level relative to control of INSIG1 and INSIG2 in the liver of broiler chickens fed diets without (control) or with $0.1 \%$ clofibrate for 4 weeks. Values are means \pm SEM, $n=24$ /group.

controls cholesterolgenic genes primarily by affecting proteolytic processing with only minor changes in the level of mRNA, whereas SREBP1c regulates lipogenic enzymes mainly by self-regulating its own transcription level due to the presence of SRE in promoter of SREBF1, or rather by changing mRNA level of $S R E B F 1$ inhibiting the proteolytic activity to cleave SREBP1c precursor into its nuclear form, indicating that SREBP1 is regulated in a different fashion than SREBP2 [35-37]. The present study demonstrated that the abundance of the precursor SREBPlc and the abundance of its nuclear 


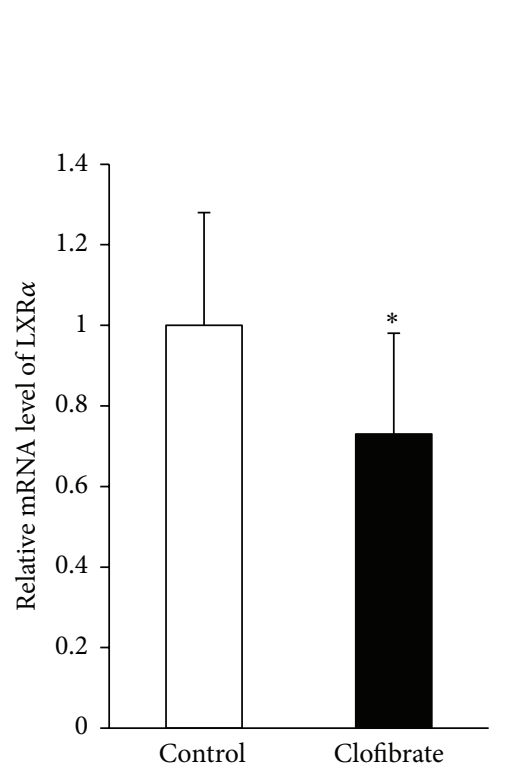

(a)

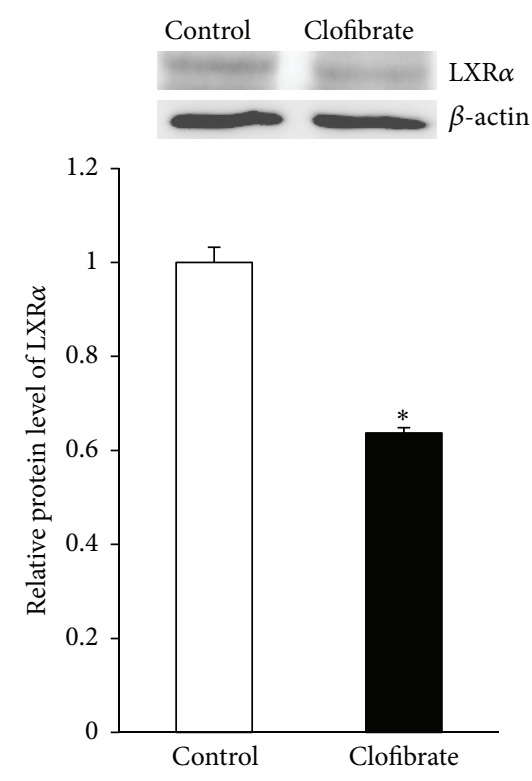

(b)

FIGURE 5: mRNA and protein level relative to control of LXR $\alpha$ in the liver of broiler chickens fed diets without (control) or with $0.1 \%$ clofibrate for 4 weeks. (a) Bars represent means \pm SEM ( $n=24$ /group) and are expressed mRNA level relative to the control group. (b) Representative immunoblot specific to nuclear $\operatorname{LXR} \alpha$ and $\beta$-actin as internal control is shown for one pool per group; immunoblots for the other pools revealed similar results. Values are means \pm SEM, $n=3$ pools/group with each pool representing 3 animals.

form were decreased in a proportional way by the clofibrate treatment. This indicates that the decrease in lipogenesis observed is mostly due to a decrease in the overall transcription of SREBF1. Peterson et al. [34] demonstrated that a short term ( $48 \mathrm{~h}$ ) treatment with trans-10, cis-12 CLA reduces lipid synthesis in bovine mammary epithelial cells through inhibition of proteolytic activation of SREBP1 and subsequent reduction in transcriptional activation of lipogenic genes. A longer-term treatment (4 weeks) with clofibrate in present study would possibly lead to a reduced abundance of SREBP1c mRNA and precursor protein. However, the mechanism by how the clofibrate lower SREBF1 mRNA levels in liver of broiler chickens remains to be explored. Taken together, these findings suggest that SREBP1c represses lipogenic genes such as FASN and GPTM and inhibits lipogenesis and lipid uptake in the liver of broiler chickens by a mechanism involving reduction of SREBP1 transcription and activation contributing to lower lipids levels in liver of broiler chickens.

Despite reporting in earlier studies that PPAR $\alpha$ activation is accompanied by an inhibition of SREBP-dependent gene expression, it is currently unknown how PPAR $\alpha$ activation mediates this effect. It has been identified that mouse and human SREBFlc gene is a direct LXR $\alpha$ target gene with two LXR response elements (LXREs) found in the SREBF1c promoter region [38-40]. This indicates that the expression of SREBFIc is regulated by $\operatorname{LXR} \alpha$. $\mathrm{LXR} \alpha$, like PPAR $\alpha$, functions usually as obligate heterodimer with retinoid $\mathrm{X}$ receptor $(\mathrm{RXR} \alpha)$ which regulates the transcription of their target genes by binding to LXRE of target promoter. A recent study has demonstrated that overexpression of PPAR $\alpha$ and treatment with PPAR $\alpha$ agonist both enhance binding of PPAR $\alpha$ to RXR $\alpha$ and decrease the amount of LXR/RXR heterodimers, leading to suppression of $\operatorname{LXR} \alpha$ ligand-activated SREBFIc expression in rat primary hepatocyte cultures and mouse liver [18]. This suggests that the mechanism for PPAR $\alpha$ inhibition of LXR $\alpha$-mediated transcriptional activity of SREBF1c could be at RXR competition between PPAR $\alpha$ and LXR $\alpha$. Besides, PPAR $\alpha$ can heterodimerize with LXR $\alpha$ and results in interference of LXR/RXR formation and inhibition of SREBF1c promoter activation [41]. Thus, our results suggest that decreased expression of nuclear LXR $\alpha$ by clofibrate may contribute to the lipid-lowering effect of PPAR $\alpha$ by inhibiting LXRdependent SREBF1c transcription in the liver of broiler chickens. However, more detailed promoter studies, for example, using reporter gene or gel-shift assays, will be needed to determine if the broiler SREBFIc gene is also a target gene of LXR $\alpha$.

Studies reported that SREBP2 controls cholesterol synthesis through cleavage of the membrane-bound precursor protein to liberate its nuclear active form in the nucleus [36, 37]. Convincing evidence has been provided that PPAR $\alpha$ activator WY 14,643, a potent PPAR $\alpha$ ligand, decreases hepatic cholesterol concentration in wild type mice, but not in PPAR $\alpha$ null mice, by alteration in membrane fatty acid composition that influenced SREBP activation, suggesting that PPAR $\alpha$ plays an important role to control SREBP2 activity and hepatic cholesterol biosynthesis [42]. The present study demonstrate that the nuclear protein level of SREBP2 is markedly less than precursor protein level by the clofibrate treatment indicating that SREBP2 controls cholesterol synthesis at the cleavage system. In contrast to our results the studies reported that the expression levels of mRNAs and proteins which involved in cholesterol biosynthesis were increased after WY 14,643 treatment in the liver of wild type mice, but in fact these 
increases seem not to be associated with hepatic de novo cholesterologenesis; thus, the present study supported the observations in mice that PPAR $\alpha$ agonist treatment does not lead to a stimulation of the hepatic cholesterol synthesis but rather decreases it $[42,43]$. We have also found in the present study that clofibrate slightly increased hepatic expression of INSIG1 and significantly that of INSIG2. In line with this, recent studies revealed that transcription of INSIG1 in rat liver and INSIG1 and INSIG2 in rat Fao cells was increased by treatment with PPAR $\alpha$ agonist WY-14,643 [10]. Similarly, rats administered an oxidized dietary fat, like frying oil, which is known to cause strong activation of hepatic PPAR $\alpha$ [44], were found to have increased mRNA levels of INSIG1 and INSIG2 in the liver [9]. Both, INSIG1 and INSIG2 are responsible for retaining the precursor forms of SREBP1 and SREBP2 within the endoplasmic reticulum thereby inhibiting the proteolytic processing of SREBPs in the Golgi $[45,46]$. Thus, it can be proposed that the upregulation of INSIGs by clofibrate causes an inhibition of the release of the SCAP-SREBP complex from INSIGs and its translocation to the Golgi, where proteolytic processing (activation) of SREBPs occurs. PPAR $\alpha$ and other $\operatorname{PPAR}$ isoforms $(\operatorname{PPAR} \gamma, \operatorname{PPAR} \delta / \beta)$ are known to stimulate transcription of target genes through binding as a complex with retinoic acid-X receptor to specific DNA sequences, called PPREs, in the regulatory region of target genes [8, 47, 48]. Interestingly, it has been recently shown that the human INSIG1 gene contains a functional PPRE, which is regulated by both, $\operatorname{PPAR} \delta$ [49] and PPAR $\gamma$ [50]. Moreover, it was shown that adenovirus induced-overexpression of PPAR $\delta$ causes induction of INSIG1 and suppression of SREBP1 activation and lipogenesis in the liver of obese diabetic mice [49] indicating that upregulation of INSIGs by clofibrate may also explain inhibition of SREBP-dependent gene expression and lipogenesis in the liver of broiler chickens. Although it remains to be shown whether the chicken genes encoding INSIG1 or INSIG2 are also regulated by $\operatorname{PPAR} \alpha$, it is wellknown that the functional PPREs of many PPAR target genes are regulated by all three PPAR isotypes. The CPT1A gene, for instance, which was used as an indicator to assess activation of PPAR $\alpha$ by clofibrate in the present study, is known to possess a functional PPRE in its promoter which is bound by $\operatorname{PPAR} \alpha, \operatorname{PPAR} \gamma$, and $\operatorname{PPAR} \delta / \beta$ target genes in broilers. However, future studies using reporter gene and gel-shift assays have to clarify whether or not the genes encoding INSIGs are PPAR target genes.

In conclusion, the results of the present study demonstrated that PPAR $\alpha$ agonist clofibrate lowers the triglyceride concentration in broiler liver by reducing transcription and activation of SREBP1 and by repressing LXR $\alpha$-mediated transcriptional activity of SREBP1, which subsequently reduced lipogenic gene expression of FASN and GPTM, whereas $\operatorname{PPAR} \alpha$ agonist clofibrate decreases cholesterol concentration in broiler liver by upregulating the expression of INSIG2 that inhibits proteolytic cleavage and activation of SREBP2, subsequently reducing SREBP2-dependent gene expression of $L D L R$ and HMGAR, thereby resulting in the decrease of synthesis capacity of triglyceride and cholesterol in the broiler liver.

\section{Conflict of Interests}

The authors declare that there is no conflict of interests regarding the publication of this paper.

\section{Acknowledgments}

This study was financially supported by 100 plans from Shanxi province and natural science foundation of Shanxi Province (2012011035-2). The authors thank Dr. Robert Ringseis and Dr. Gaiping Wen (Institute of Animal Nutrition and Nutritional Physiology, Justus-Liebig-Universität Gießen, Germany) for supporting technique and for critical discussion of the paper. The authors are also very grateful to Honggang Zhang, Aifang Fan, and Xia Wu for performing the feeding experiment and Junlong Xue and Jingming Yao for sample collection.

\section{References}

[1] C. Yokoyama, X. Wang, M. R. Briggs et al., "SREBP-1, a basichelix-loop-helix-leucine zipper protein that controls transcription of the low density lipoprotein receptor gene," Cell, vol. 75, no. 1, pp. 187-197, 1993.

[2] X. Hua, C. Yokoyama, J. Wu et al., "SREBP-2, a second basichelix-loop-helix-leucine zipper protein that stimulates transcription by binding to a sterol regulatory element," Proceedings of the National Academy of Sciences of the United States of America, vol. 90, no. 24, pp. 11603-11607, 1993.

[3] B. Desvergne and W. Wahli, "PPAR: a key nuclear factor in nutrient/gene interactions," in Inducible Gene Expression, A. P. Baurerle, Ed., vol. 1, pp. 142-176, Birkhäuser, Boston, Mass, USA, 1994.

[4] K. Schoonjans, B. Staels, and J. Auwerx, "Role of the peroxisome proliferator-activated receptor (PPAR) in mediating the effects of fibrates and fatty acids on gene expression," Journal of Lipid Research, vol. 37, no. 5, pp. 907-925, 1996.

[5] M. S. Brown and J. L. Goldstein, "The SREBP pathway: regulation of cholesterol metabolism by proteolysis of a membranebound transcription factor," Cell, vol. 89, no. 3, pp. 331-340, 1997.

[6] M. S. Brown and J. L. Goldstein, "A proteolytic pathway that controls the cholesterol content of membranes, cells, and blood," Proceedings of the National Academy of Sciences of the United States of America, vol. 96, no. 20, pp. 11041-11048, 1999.

[7] B. Desvergne and W. Wahli, "Peroxisome proliferator-activated receptors: nuclear control of metabolism," Endocrine Reviews, vol. 20, no. 5, pp. 649-688, 1999.

[8] S. Mandard, M. Müller, and S. Kersten, "Peroxisome proliferator-activated receptor alpha target genes," Cellular and Molecular Life Sciences, vol. 61, no. 4, pp. 393-416, 2004.

[9] A. Koch, B. König, J. Spielmann, A. Leitner, G. I. Stangl, and K. Eder, "Thermally oxidized oil increases the expression of insulin-induced genes and inhibits activation of sterol regulatory element-binding protein-2 in rat liver," Journal of Nutrition, vol. 137, no. 9, pp. 2018-2023, 2007.

[10] B. Koenig, A. Koch, J. Spielmann, C. Hilgenfeld, G. I. Stangl, and K. Eder, "Activation of PPAR $\alpha$ lowers synthesis and concentration of cholesterol by reduction of nuclear SREBP-2," Biochemical Pharmacology, vol. 73, no. 4, pp. 574-585, 2007.

[11] B. König, A. Koch, J. Spielmann et al., "Activation of PPAR $\alpha$ and PPAR $\gamma$ reduces triacylglycerol synthesis in rat hepatoma cells by 
reduction of nuclear SREBP-1," European Journal of Pharmacology, vol. 605, no. 1-3, pp. 23-30, 2009.

[12] K. Eder, A. Suelzle, P. Skufca, C. Brandsch, and F. Hirche, "Effects of dietary thermoxidized fats on expression and activities of hepatic lipogenic enzymes in rats," Lipids, vol. 38, no. 1, pp. 31-38, 2003.

[13] C. Song, J. M. Kokontis, R. A. Hiipakka, and S. Liao, "Ubiquitous receptor: a receptor that modulates gene activation by retinoic acid and thyroid hormone receptors," Proceedings of the National Academy of Sciences of the United States of America, vol. 91, no. 23, pp. 10809-10813, 1994.

[14] P. J. Willy, K. Umesono, E. S. Ong, R. M. Evans, R. A. Heyman, and D. J. Mangelsdorf, "LXR, a nuclear receptor that defines a distinct retinoid response pathway," Genes and Development, vol. 9, no. 9, pp. 1033-1045, 1995.

[15] J. R. Schultz, H. Tu, A. Luk et al., "Role of LXRs in control of lipogenesis," Genes \& Development, vol. 14, no. 22, pp. 2831-2838, 2000.

[16] C. E. Juge-Aubry, A. Gorla-Bajszczak, A. Pernin et al., "Peroxisome proliferator-activated receptor mediates cross-talk with thyroid hormone receptor by competition for retinoid X receptor: possible role of a leucine zipper-like heptad repeat," The Journal of Biological Chemistry, vol. 270, no. 30, pp. 18117-18122, 1995.

[17] A. Fernández-Alvarez, M. Soledad Alvarez, R. Gonzalez, C. Cucarella, J. Muntané, and M. Casado, "Human SREBF1c expression in liver is directly regulated by peroxisome proliferator-activated receptor $\alpha$ (PPAR $\alpha)$," The Journal of Biological Chemistry, vol. 286, no. 24, pp. 21466-21477, 2011.

[18] T. Yoshikawa, T. Ide, H. Shimano et al., "Cross-talk between peroxisome proliferator-activated receptor (PPAR) $\alpha$ and liver $X$ receptor (LXR) in nutritional regulation of fatty acid metabolism. I. PPARs suppress sterol regulatory element binding protein-1c promoter through inhibition of LXR signaling," Endocrinology, vol. 17, no. 7, pp. 1240-1254, 2003.

[19] J. D. Horton, J. L. Goldstein, and M. S. Brown, "SREBPs: activators of the complete program of cholesterol and fatty acid synthesis in the liver," The Journal of Clinical Investigation, vol. 109, no. 9, pp. 1125-1131, 2002.

[20] F. Gondret, P. Ferré, and I. Dugail, "ADD-1/SREBP-1 is a major determinant of tissue differential lipogenic capacity in mammalian and avian species," Journal of Lipid Research, vol. 42, no. 1, pp. 106-113, 2001.

[21] G. P. Laliotis, I. Bizelis, and E. Rogdakis, “Comparative approach of the de novo fatty acid synthesis (lipogenesis) between ruminant and non ruminant mammalian species: from biochemical level to the main regulatory lipogenic genes," Current Genomics, vol. 11, no. 3, pp. 168-183, 2010.

[22] E. K. O’Hea and G. A. Leveille, "Lipid biosynthesis and transport in the domestic chick (Gallus domesticus)," Comparative Biochemistry and Physiology, vol. 30, no. 1, pp. 149-159, 1969.

[23] E. K. O'Hea and G. A. Leveille, "Influence of fasting and refeeding on lipogenesis and enzymatic activity of pig adipose tissue," Journal of Nutrition, vol. 99, no. 3, pp. 345-352, 1969.

[24] A. M. Mildner and S. D. Clarke, "Porcine fatty acid synthase: cloning of a complementary DNA, tissue distribution of its mRNA and suppression of expression by somatotropin and dietary protein," Journal of Nutrition, vol. 121, no. 6, pp. 900-907, 1991.

[25] P. Griminger, "Lipid metabolism," in Avian Physiology, pp. 345358, Springer, 1986.
[26] M. Shibani, J. Keller, H. Kluge et al., "Effects of activation of peroxisome proliferatoractivated receptor-a by clofibrate on carnitine homeostasis in laying hens," African Journal of Agricultural Research, vol. 7, no. 10, pp. 1450-1455, 2012.

[27] A. Hara and N. S. Radin, "Lipid extraction of tissues with a lowtoxicity solvent," Analytical Biochemistry, vol. 90, no. 1, pp. 420426, 1978.

[28] J. L. De Hoff, L. M. Davidson, and D. Kritchevsky, "An enzymatic assay for determining free and total cholesterol in tissue," Clinical Chemistry, vol. 24, no. 3, pp. 433-435, 1978.

[29] J. Keller, R. Ringseis, A. Koch, I. Lukas, H. Kluge, and K. Eder, "Supplementation with L-carnitine downregulates genes of the ubiquitin proteasome system in the skeletal muscle and liver of piglets," Animal, vol. 6, no. 1, pp. 70-78, 2012.

[30] R. Ringsei, S. Rosenbaum, D. K. Gessner et al., "Supplementing obese Zucker rats with niacin induces the transition of glycolytic to oxidative skeletal muscle fibers," Journal of Nutrition, vol. 143, no. 2, pp. 125-131, 2013.

[31] X. Zhou, G. Wen, R. Ringseis, and K. Eder, "Short communication: the pharmacological peroxisome proliferator-activated receptor $\alpha$ agonist WY-14,643 increases expression of novel organic cation transporter 2 and carnitine uptake in bovine kidney cells," Journal of Dairy Science, vol. 97, no. 1, pp. 345-349, 2014.

[32] J. Vandesompele, K. De Preter, F. Pattyn et al., "Accurate normalization of real-time quantitative RT-PCR data by geometric averaging of multiple internal control genes," Genome Biology, vol. 3, no. 7, 2002.

[33] J. Hellemans, G. Mortier, A. De Paepe, F. Speleman, and J. Vandesompele, "qBase relative quantification framework and software for management and automated analysis of real-time quantitative PCR data," Genome Biology, vol. 8, no. 2, article R19, 2007.

[34] D. G. Peterson, E. A. Matitashvili, and D. E. Bauman, "The inhibitory effect of trans-10, cis-12 CLA on lipid synthesis in bovine mammary epithelial cells involves reduced proteolytic activation of the transcription factor SREBP-1," Journal of Nutrition, vol. 134, no. 10, pp. 2523-2527, 2004.

[35] V. C. Hannah, J. Ou, A. Luong, J. L. Goldstein, and M. S. Brown, "Unsaturated Fatty Acids Down-regulate SREBP Isoforms 1a and 1c by Two Mechanisms in HEK-293 Cells,", Journal of Biological Chemistry, vol. 276, no. 6, pp. 4365-4372, 2001.

[36] M. Amemiya-Kudo, H. Shimano, A. H. Hasty et al., "Transcriptional activities of nuclear SREBP-1a, -1c, and -2 to different target promoters of lipogenic and cholesterogenic genes," Journal of Lipid Research, vol. 43, no. 8, pp. 1220-1235, 2002.

[37] H. Shimano, "Sterol regulatory element-binding proteins (SREBPs): transcriptional regulators of lipid synthetic genes," Progress in Lipid Research, vol. 40, no. 6, pp. 439-452, 2001.

[38] J. J. Repa, G. Liang, J. Ou et al., "Regulation of mouse sterol regulatory element-binding protein-1c gene (SREBP-1c) by oxysterol receptors, LXR $\alpha$ and LXR $\beta$," Genes and Development, vol. 14, no. 22, pp. 2819-2830, 2000.

[39] J. J. Repa, S. D. Turley, J.-M. A. Lobaccaro et al., "Regulation of absorption and ABC1-mediated efflux of cholesterol by RXR heterodimers," Science, vol. 289, no. 5484, pp. 1524-1529, 2000.

[40] T. Yoshikawa, H. Shimano, M. Amemiya-Kudo et al., "Identification of liver $\mathrm{X}$ receptor-retinoid $\mathrm{X}$ receptor as an activator of the sterol regulatory element-binding protein 1c gene promoter," Molecular and Cellular Biology, vol. 21, no. 9, pp. 29913000, 2001. 
[41] T. Ide, H. Shimano, T. Yoshikawa et al., "Cross-talk between peroxisome proliferator-activated receptor (PPAR) $\alpha$ and liver $\mathrm{X}$ receptor (LXR) in nutritional regulation of fatty acid metabolism. II. LXRs suppress lipid degradation gene promoters through inhibition of PPAR signaling," Molecular Endocrinology, vol. 17, no. 7, pp. 1255-1267, 2003.

[42] B. L. Knight, A. Hebbach, D. Hauton et al., "A role for PPAR $\alpha$ in the control of SREBP activity and lipid synthesis in the liver," Biochemical Journal, vol. 389, no. 2, pp. 413-421, 2005.

[43] M. Fidaleo, S. Arnauld, M.-C. Clémencet et al., "A role for the peroxisomal 3-ketoacyl-CoA thiolase B enzyme in the control of PPAR $\alpha$-mediated upregulation of SREBP-2 target genes in the liver," Biochimie, vol. 93, no. 5, pp. 876-891, 2011.

[44] R. Ringseis and K. Eder, "Regulation of genes involved in lipid metabolism by dietary oxidized fat," Molecular Nutrition \& Food Research, vol. 55, no. 1, pp. 109-121, 2011.

[45] D. Yabe, M. S. Brown, and J. L. Goldstein, "Insig-2, a second endoplasmic reticulum protein that binds SCAP and blocks export of sterol regulatory element-binding proteins," Proceedings of the National Academy of Sciences of the United States of America, vol. 99, no. 20, pp. 12753-12758, 2002.

[46] T. Yang, P. J. Espenshade, M. E. Wright et al., "Crucial step in cholesterol homeostasis: sterols promote binding of SCAP to INSIG-1, a membrane protein that facilitates retention of SREBPs in ER," Cell, vol. 110, no. 4, pp. 489-500, 2002.

[47] A. IJpenberg, E. Jeannin, W. Wahli, and B. Desvergne, "Polarity and specific sequence requirements of peroxisome proliferatoractivated receptor (PPAR)/retinoid X receptor heterodimer binding to DNA. A functional analysis of the malic enzyme gene PPAR response element," The Journal of Biological Chemistry, vol. 272, no. 32, pp. 20108-20117, 1997.

[48] G. Wen, H. Kühne, C. Rauer, R. Ringseis, and K. Eder, "Mouse $\gamma$-butyrobetaine dioxygenase is regulated by peroxisome proliferator-activated receptor $\alpha$ through a PPRE located in the proximal promoter," Biochemical Pharmacology, vol. 82, no. 2, pp. 175-183, 2011.

[49] X. Qin, X. Xie, Y. Fan et al., "Peroxisome proliferator-activated receptor-delta induces insulin-induced gene- 1 and suppresses hepatic lipogenesis in obese diabetic mice," Hepatology, vol. 48, no. 2, pp. 432-441, 2008.

[50] H. R. Kast-Woelbern, S. L. Dana, R. M. Cesario et al., "Rosiglitazone induction of Insig-1 in white adipose tissue reveals a novel interplay of peroxisome proliferator-activated receptor $\gamma$ and sterol regulatory element-binding protein in the regulation of adipogenesis," Journal of Biological Chemistry, vol. 279, no. 23, pp. 23908-23915, 2004. 


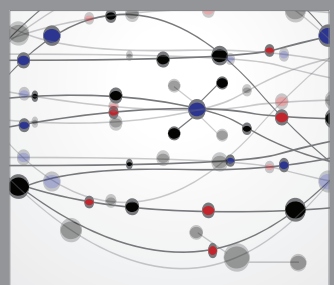

The Scientific World Journal
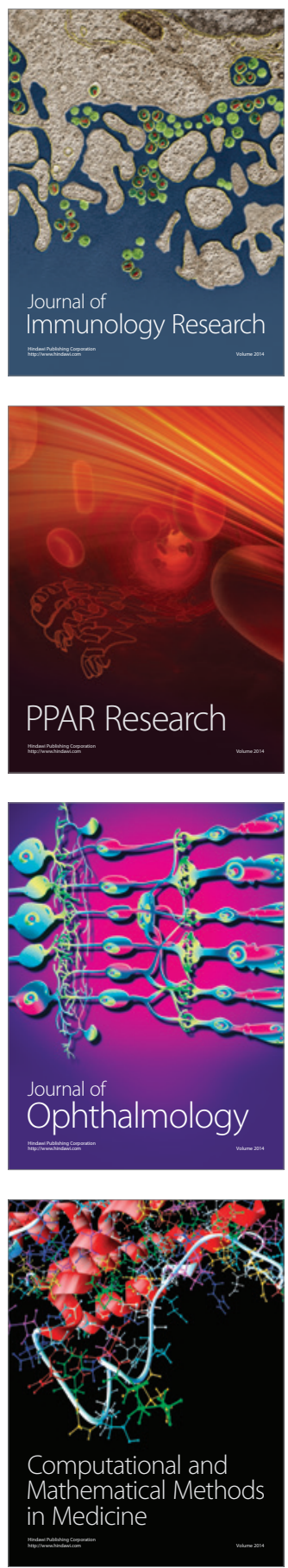

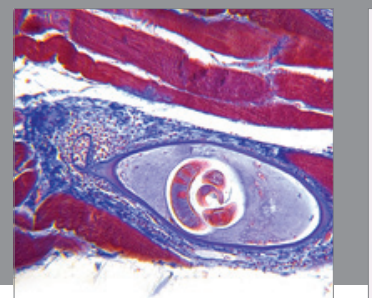

Gastroenterology

Research and Practice
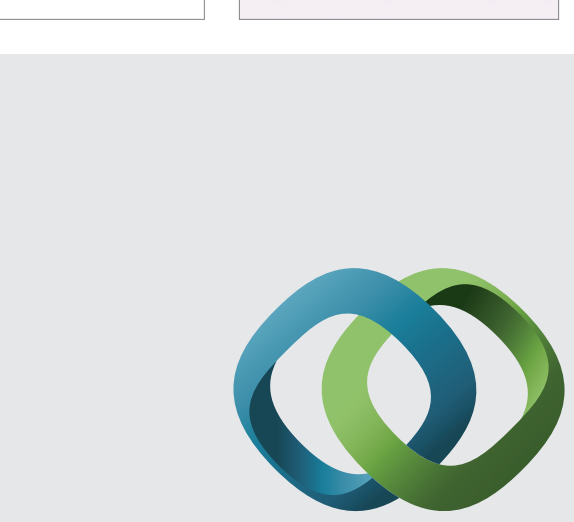

\section{Hindawi}

Submit your manuscripts at

http://www.hindawi.com
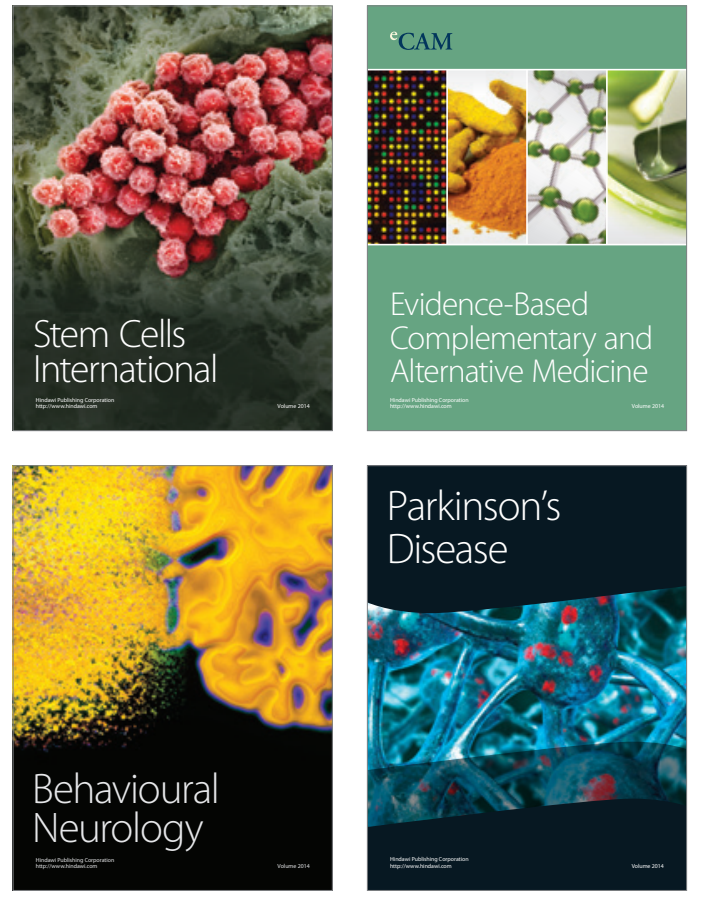
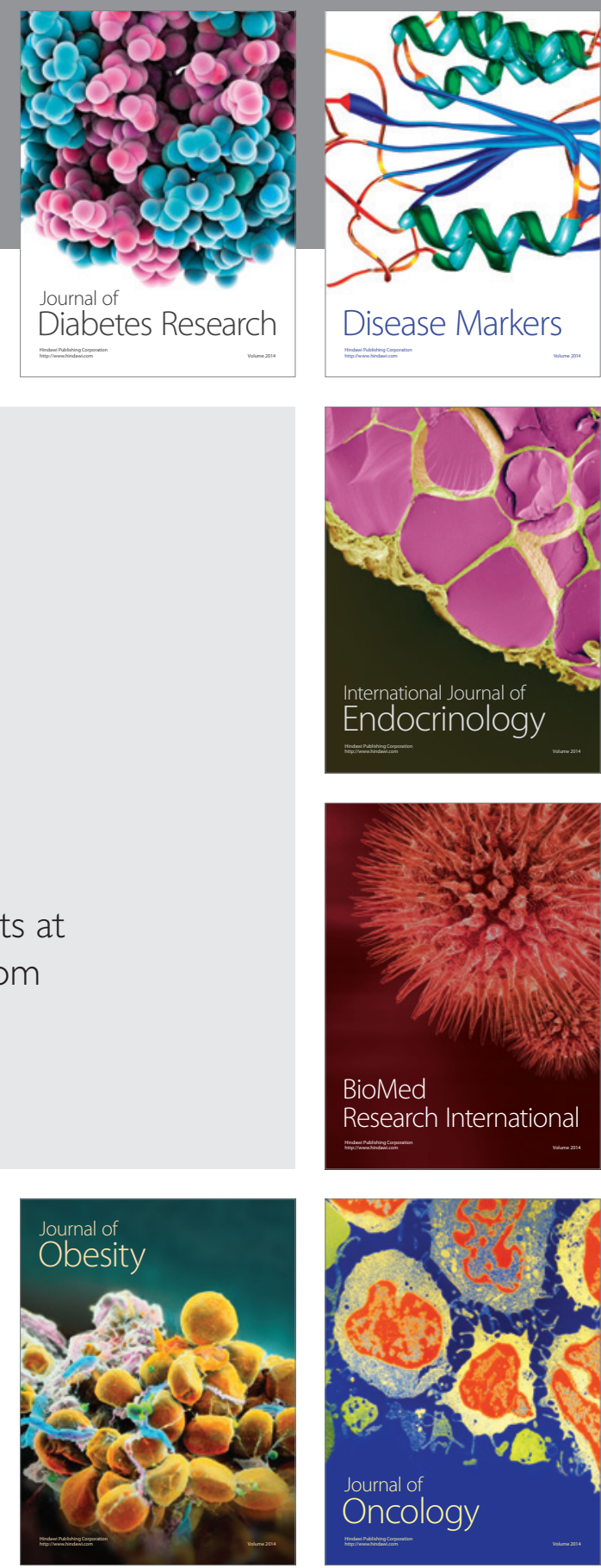

Disease Markers
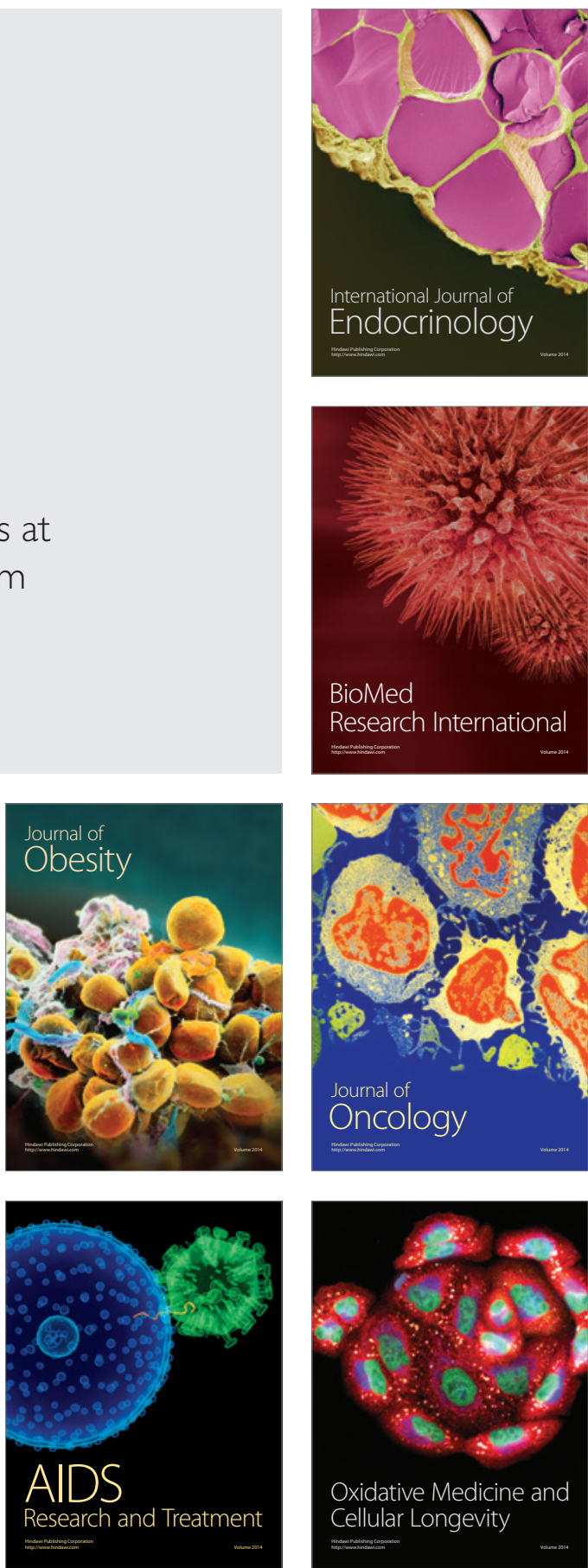